\title{
SCANNING ELECTRON MICROSCOPIC EXAMINATION OF THE DEPOSITS COVERING THE SOUTHEASTERN SLOPE OF THE ONNENVUORI HILL IN LAMMI, SOUTHERN FINLAND
}

\author{
Milton Núñez and Pentiti Alhonen
}

\begin{abstract}
Núnez, Milton and Almonen, Pentri 1974: Scanning electron microscopic examination of the deposits covering the southeastern slope of the Onnenvuori hill in Lammi, southern Finland. Bull. Geol. Soc. Finland 46, 109-116.
\end{abstract}

A sedimentological study, including granulometric, morphoscopic and scanning electron microscopic analyses, was made on three samples from the deposits covering the hill of Onnenvuori in Lammi. The results obtained from the analyses were used in reconstructing the environmental episodes undergone by the material. On the basis of this work it was concluded that a similar sedimentological study on a larger scale may help to elucidate the environmental history of the Lammi coversands.

Milton Núñez and Pentii Albonen, Department of Geology and Paleontology, University of Helsinki, SF-00170 Helsinki 17, Finland.

\section{Introduction}

In the vicinities of the village of Lammi, Southern Finland, there occurs a fine-grained sediment covering a relatively wide area in a sheet-like manner. The deposits were first mentioned by V. Okko (1957 a, b) and more recently by Jauhiainen (1972) and Wiśniewski (1973). Both V. Okko and Jauhiainen seem to agree in their interpretation of the deposits: a layer of variable thickness composed mainly of fine sand probably of eolian origin. On the other hand, the investigations carried out by Wiśniewski (1973) failed either to confirm or to deny the eolian nature of the cover deposits.

Three samples were taken from the Onnenvuori hill by a Geology class during a field trip in the fall of 1972 (see Fig. 1 for sampling sites). At their return, Mr. M. Eronen suggested that we should analyze the samples utilizing the same methods Nún̄ez (1972) had used when studying French cave sediments. The present paper is merely a report of the results obtained from analyzing the Onnenvuori samples and it does not attempt to solve the problem concerning the origin of Lammi cover deposits as a whole. Its main purpose is to give some information about the nature of the material covering the Onnenvuori hill and to determine whether it would be possible to reconstruct by these methods the processes which contributed to the formation of the Lammi cover deposits.

\section{Methods}

Granulometry. The granulometric analysis was done by sieving the coarser fractions and by determining the finer fractions according to 


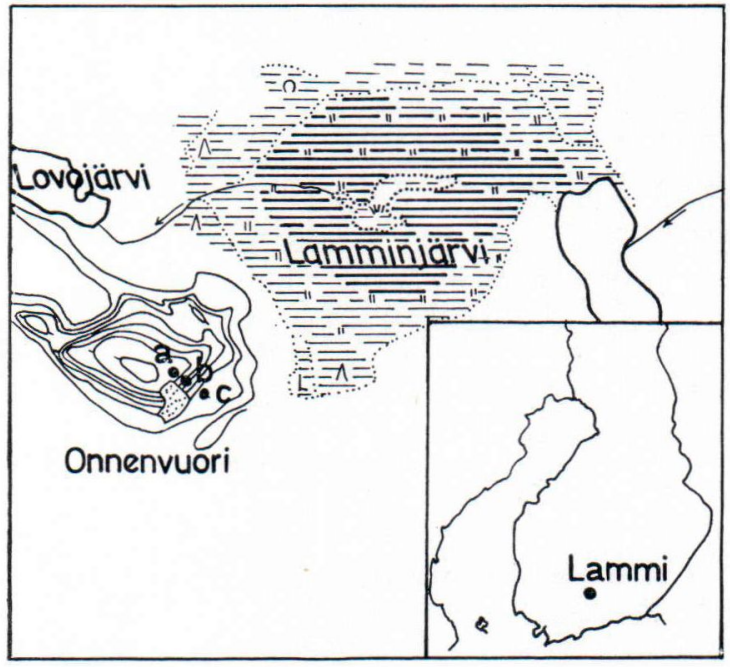

Fig 1. Map of the area showing the Onnenvuori hill and the location of the sampling sites. At the Onnenvuori the highest and lowest contour lines represent respectively 160 and $130 \mathrm{~m}$ a.s.l.

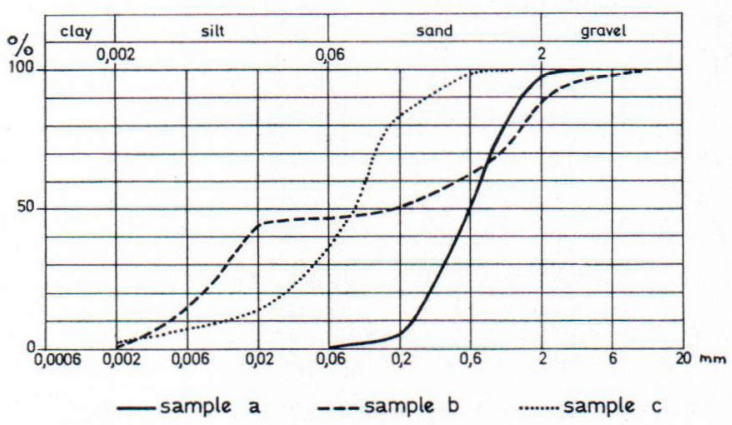

Fig. 2. Cumulative grain-size curves.

the hydrometre method. The results are given as cumulative graphs in Fig. 2.

Morphoscopy. The degree of roundness of the sand grains was observed through a low-powered binocular microscope. This method has been described by Cailleux $(1942,1952,1959)$ and it has been used by M. Okko (1962) and Seppälä $(1969,1971)$ in Finland; but in order to attack the particular problems presented by the Lammi cover deposits some modifications were made. Since one question was the possibility of fine eolian material being mixed with coarser non- eolian sediments (V. Okko 1957 a, b; Jauhiainen 1972) the size range of the grains studied was extended to $0.3-1.3 \mathrm{~mm}$. The degree of roundness was determined according to Pettijonhn's scale (in Köster 1964, p. 188-189). The following categories were differentiated: angular, subangular, sub-rounded and rounded.

Following Cailleux's methods, the occurrence of frosting i.e. matt surfaces due to eolian abrasion on the quartz grains, was also observed and recorded. The two following types were distinguished:

1) Not frosted, including those grains showing little or no frosting; and

2) Frosted, including frosted grains and those displaying considerable frosting on their edges and protruding parts.

A total of 500 grains (100 from sample a and 200 from each b and c) was examined and classified according to the above mentioned criteria. The results obtained are summarized in the diagrams of Fig. 3.

Submicroscopic surface texture analysis. Although the occurrence of frosting has long been used as a criterion for identifying eolian abrassion on sand grains, more recent research with the scanning electron microscope (SEM) has increased the importance and possibilities of surface texture analysis. According to several authors (among others Cailleux and Schneider 1968; Krinsley and Donahue 1968; Krinsley and Margolis 1969, 1971; Krinsley and Cavallero 1970; Krinsley and Doornkamp 1973) the SEM has permitted the identification of certain series of surface textures that seem to be characteristic of particular environments.

The SEM of the Department of Agricultural and Forest Zoology of the University of Helsinki was used in the examination of the Onnenvuori material. The surface textures of 45 grains (15 from each sample) were studied and compared to those described in the literature mentioned above. All three samples showed surface textures characteristic of glacial, littoral and eolian 


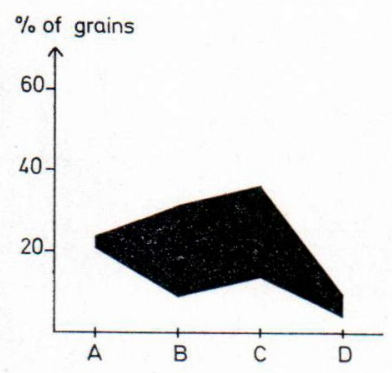

Sample a

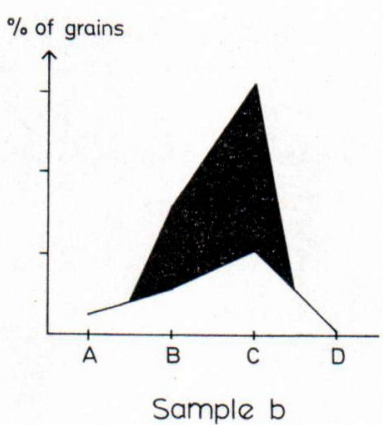

Sample b

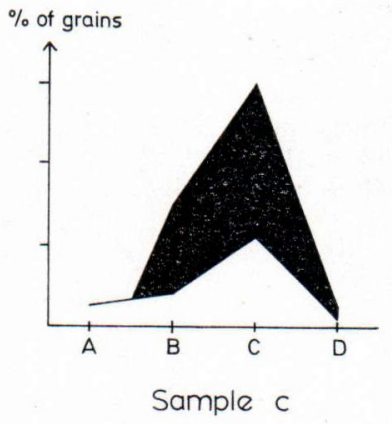

Frosting :

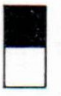

Frosted

Not frosted

Fig. 3. Roundness and frosting of the quartz sand grains.

environments. In addition to the 45 grains, two groups of grains belonging to the finer fractions $(<0.2 \mathrm{~mm})$ of samples $\mathrm{b}$ and $\mathrm{c}$ were also examined. Micrographs of some of the surface textures observed are given and explained in figures $4-11$.

\section{Discussion}

The genesis of the Onnenvuori hill as a glaciofluvial delta is discussed by Wiśniewski (1973). The height of the Onnenvuori summit (c. $162 \mathrm{~m}$ a.s.1.) coincides roughly with the B III level in the area and the hillock stands about $30 \mathrm{~m}$ above the surrounding country. The drainage of the Baltic Ice Lake resulted in a $28 \mathrm{~m}$ drop of the water level (from B III to Y I) and took place around $10200 \mathrm{BP}$ (Donner 1969). The drainage brought about the emergence of the Onnenvuori hill and other areas presently situated approximately between $130 \mathrm{~m}$ and $160 \mathrm{~m}$ a.s.l. (Jauhiainen 1972). The extent of the emerged areas can be seen in M. Okko's maps (1972, pp. 118-119).

Once the Baltic Ice Lake had drained, the newly exposed areas must have undergone a period of intense erosional processes - mainly slope-washing, solifluction and eolization which must have lasted until vegetation cover spread gradually into the Lammi region. The Lammi cover deposits are undoubtedly closely related to the eolian activity that took place during this period. The examination of the Onnenvuori samples reflected this eolian episode. The differences between the samples are mainly due to differential action of the erosional and depositional factors on each sampling site.

Sample a is well sorted with over $90 \%$ of its material within the medium and coarse sand grades. The cumulative curve seems to suggest beach material when compared with Aartolahti's (1972) ranges for Finnish eolian and beach ridge deposits (see Fig. 12). A beach origin is also supported by the occurrence of submicroscopic littoral textures on 11 of the 15 grains examined with the SEM. The SEM also revealed the precence of eolian textures on 8 of the grains observed. Since the eolian textures were found to be superimposed to the glacial and littoral textures, it follows that the eolian episode must have taken place after the drainage of the Baltic Ice Lake.

The granulometric composition of sample b is more difficult to interprete. It resembles that 


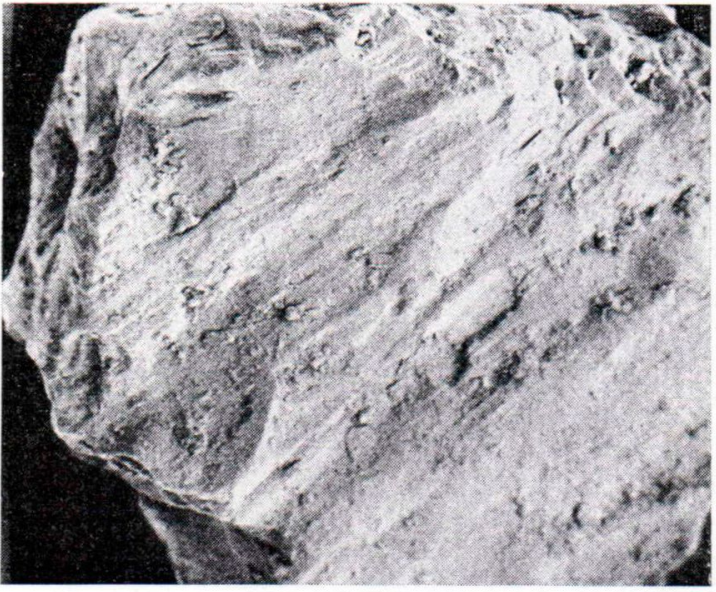

Fig. 4. Sample a (magn. $250 \times$ ). This micrograph shows a fairly flat striated surface on a sub-rounded grain (No. 12 of Pettijohn's scale). The striations are probably due to mechanically broken cleavage planes which were broken when a portion or portions of the grain were separated off, possibly during glacial grinding. Conchoidal breakage patterns can be seen at the upper right corner of the picture at the edge of the striated surface. The conchoidal fractures grade into uptuined plates, but these are hardly visible in the photograph. The grain reflects a strong mechanical episode followed by subaqueous and eolian stages. The criteria for subaqueous environment have been V-shaped marks and blocky conchoidal fractures, for eolization upturned plates.

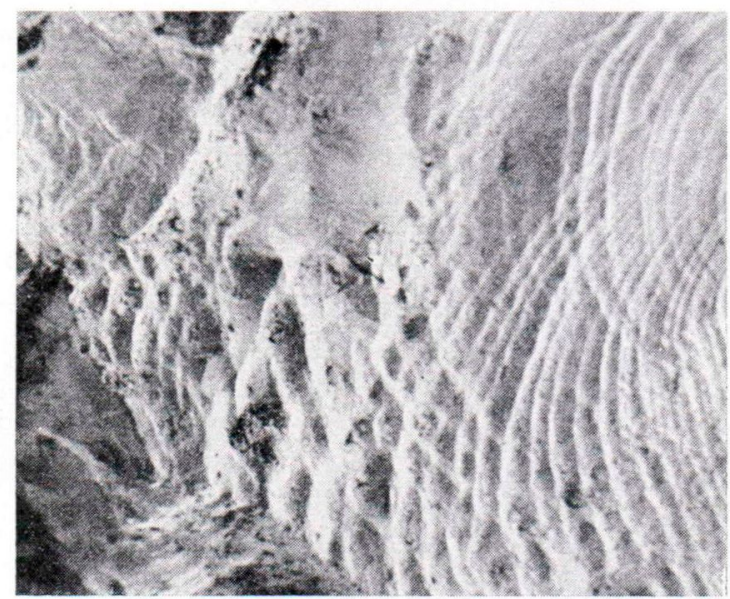

Fig. 6. Sample b (magn. $300 \times$ ). This grain presents a rather large surface covered with conchoidal breakage patterns. The photographed area is almost dominated by two fractures spreading from the right and which are probably the result of two different impacts. The high relief and conchoidal patterns are typically glacial textures. The occurrence of upturned plates on some of the edges and protruding parts of the grain hints at an eolian episode, but its influence on this grain is rather poor.

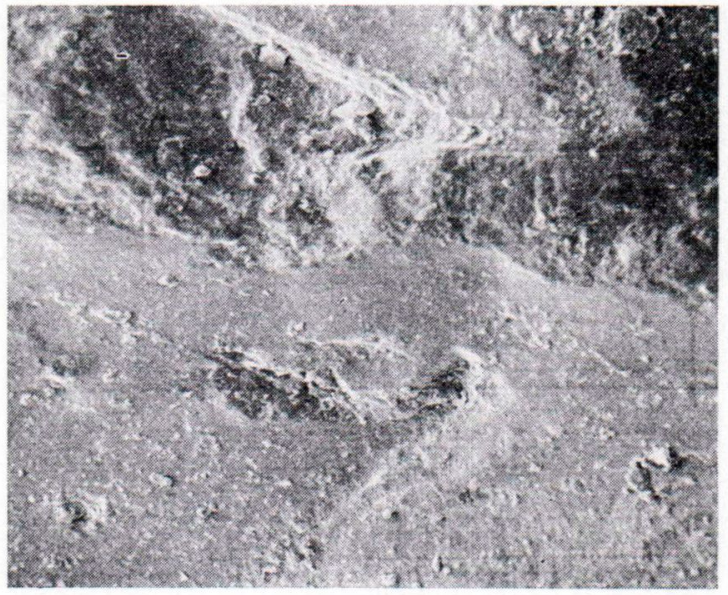

Fig. 5. Sample a (magn. $1000 \times)$. This micrograph despicts mechanical V-shaped patterns, which are usually associated with littoral environments. One of the two larger V-shaped indentations is a sattelite $\mathrm{V}$ of the groove running across the picture. The size, density and orientation of the $\mathrm{V}$-shaped indentations on this and other grains from sample a suggest a low to medium energy beach.



Fig. 7. Sample b (magn. $1000 \times$ ). This is a close-up of the surface of an eolian grain completely covered with upturned plates. Upturned plates are characteristic of eolian environments and they probably cause the frosty appearance under the binocular microscope. 


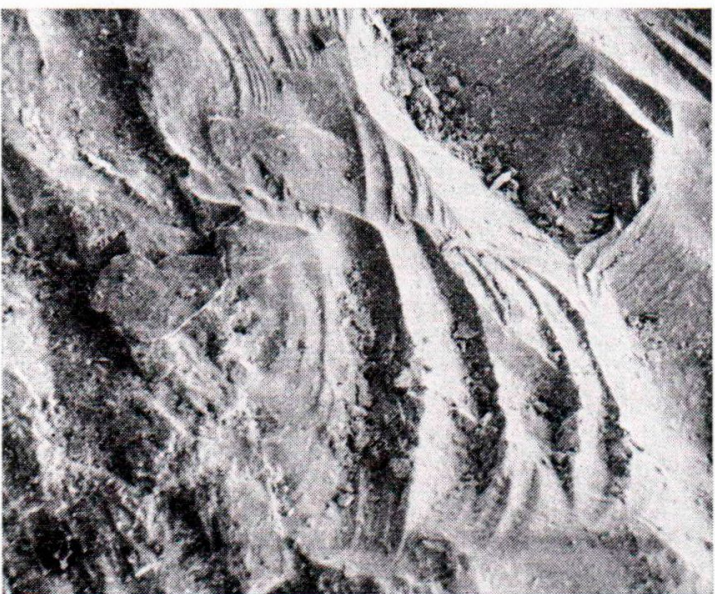

Fig. 8. Sample c (magn. $500 \times)$. This is a micrograph illustrating the conchoidal breakage patterns presented by a glacial grain. The variety in size of the conchoidal fractures is characteristic of glacial grains. The right side of the photograph displays a rather fresh surface because this portion is situated within a depression but the surface becomes rougher towards the left where it is less protected. This roughness is due to the presence of upturned plates. Note that there is also roughness and mechanical breakage on the protruding portions of the conchoidal fractures. The upturned plates as well as the roughness and mechanical breakage on the protruding portions are probably the result of eolian transport.

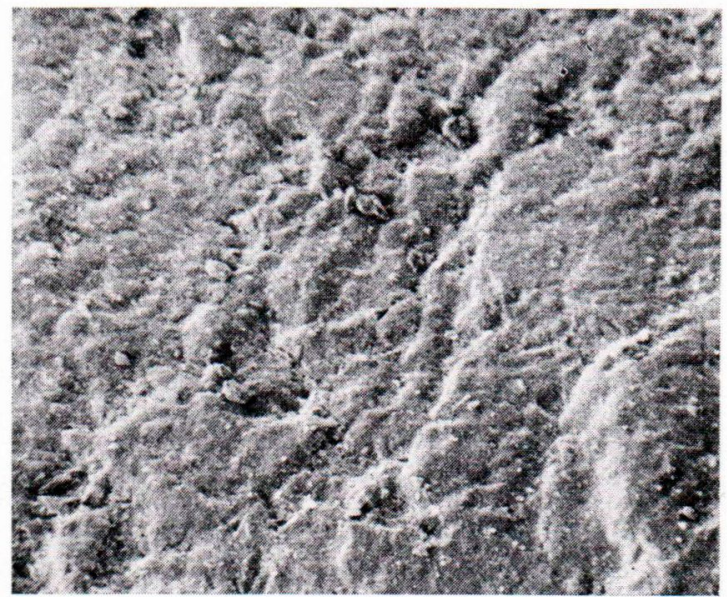

Fig. 9. Sample c (magn. $2000 \times$ ). As in Fig. 7, this micrograph shows again upturned cleavage plates on an eolian grain. The apparently subdued topography is due to incorrect focusing.

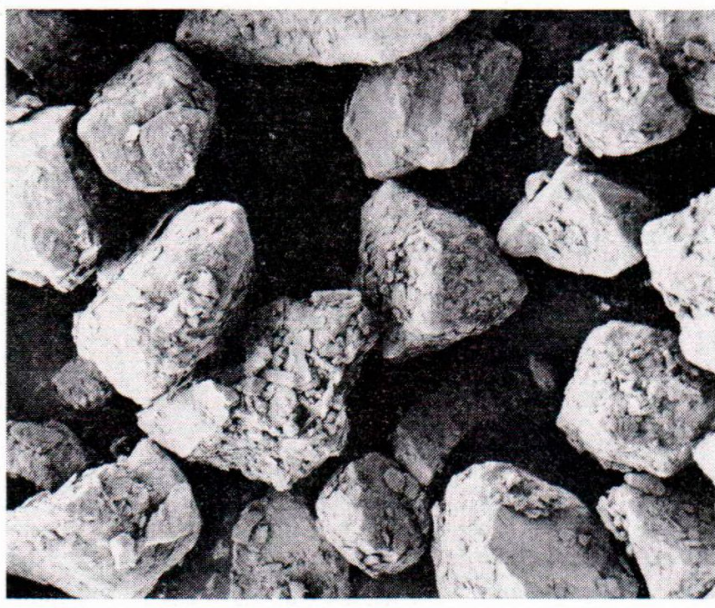

Fig. 10. Sample b (magn. $250 \times$ ). The micrograph shows a group of grains belonging to the fine fractions $(<0.2$ $\mathrm{mm}$ ). The grains have a distinct facetted appearance very similar to that of photographed loess particles. (Compare with Smalley and Taylor 1970 , p. 30 and with Krinsley and Doornkamp 1973, pp. 51-52). Adhering particles are also present as in the loess photographs.

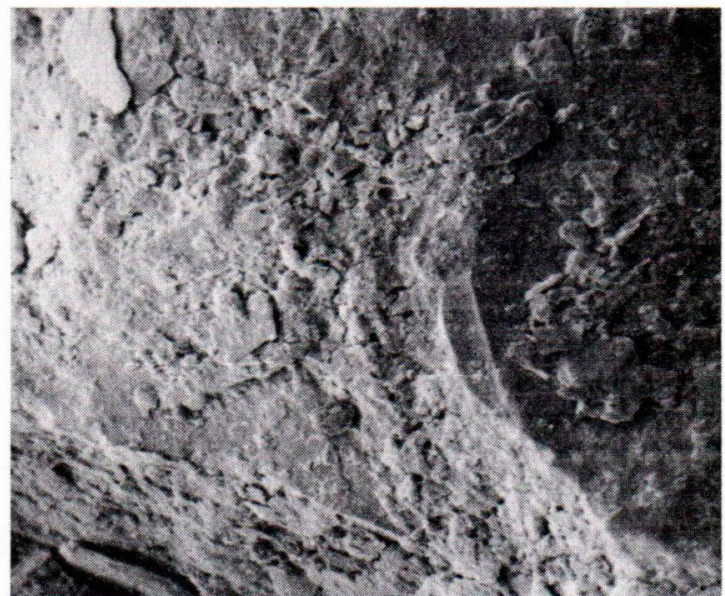

Fig. 11. Sample c (magn. $2500 \times$ ). This is a close-up of one of the grains in Fig. 10. The rather smooth surfaces almost devoid of conchoidal patterns suggest that the facets are due to mechanical breakage along cleavage planes. Upturned plates occur, but they are never as common as in the larger-sized grains. This seems to indicate that the finer-sized grains did not undergo as much saltation as their larger counterparts. 


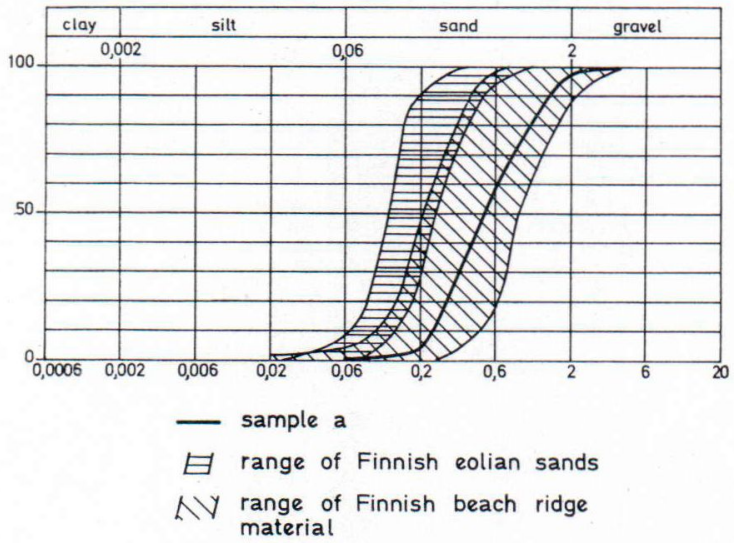

Fig. 12. Comparison between the grain size composition of sample a and Aartolahti's (1972) ranges for Finnish colian and bech ridge materials.

of the glaciofluvial material from the area (see Wiśniewski 1973) but it shows a distinct impoverishment of the $0.02-0.5 \mathrm{~mm}$ fraction. This may be connected with eolian activity, since this particle size range is generally the one most affected by winds. This feature is not restricted to the Onnenvuori slopes; the fraction $0.02-0.2$ $\mathrm{mm}$ is poorly represented in the material covering the nearby Hiidenhoilo hill (see Wiśniewski 1973, p. 27). On the other hand, the combination of materials of different origins $\left(^{*}\right)$ would explain the mentioned feature equally well.

The cumulative graph of sample c is extremely similar to those of Jauhiainen's (1972) and V. Okko's (1957 a, b) samples, and on this basis, sample c can be identified with the material which Jauhiainen refers to as »Lammin lössi» (the Lammi loess). Strictly speaking the material is not loess (see Butzer 1964, Smalley and Taylor 1970 and Flint 1971 for definitions

*) - During Núñez's visit to the University of Bordeaux in the fall of 1973 Dr. J.-P. Texier from Laboratory of Quaternary Geology, after reading the manuscript of this work, commented on the similarity of the granulometric graph of sample b and the graphs of some levels from the site of Malpas. He pointed out that the peculiar feature seen in the graph of sample b may be due to the mixing of two different materials by solifluction, as in Malpas (see Texier and Paquereau 1973, p. 45). This is indeed a very possible explanation since solifluction must have been common in the newly emerged areas, at least during the melting seasons. of loess) but rather some sort of sandsheet or coversand. According to Butzer (1964) sandsheets form an intermediate class of eolian deposits characterized by "particle sizes in the silt to medium sand grades with the maxima in the fine sand category». (Compare this definition with the composition of sample $c$ in Fig. 2).

The similarity of the results obtained from the morphoscopic analysis of samples b and c suggests that at least the $0.3-1.3 \mathrm{~mm}$ range of both samples has a common or very similar source. The high percentage of sub-angular and sub-rounded grains with matt surfaces is a clear indication that the studied size range has undergone an episode of wind-induced saltation. The SEM examination showed close affinities between samples b and c. Upturned plates occurred on nearly all the grains, 12 from sample b and 14 from c. Glacial and to a lesser extent littoral textures were present, but these were always found overridden by upturned plates.

The finer fraction $(<0.2 \mathrm{~mm})$ presented no especial surface textures but the grains had a distinct facetted appearance. This facetting is due to the existence of smooth rather flat surfaces. Very similar facetting is shown by micrographs of loess particles in Smalley and Tailor (1970) and Krinsley and in Krinsley and Doornkamp (1973). These micrographs also show smaller particles adhered to the surface of the loess particles in the same fashion as in figures 10 and 11.

The similarities between the loess particles and the finer fractions $(<0.2 \mathrm{~mm})$ of samples $\mathrm{b}$ and $\mathrm{c}$ suggest some connection with eolian activity, but this suggestion has to be taken with caution until comparative information on water-laid silt particles is available. On the other hand, the sandsheet nature of the Lammi cover deposits agrees well with the idea of a conjunct deposition of sand and silt grades. The empirical approach illustrated in Fig. 13 is also suggestive.

The eolian activity in the Lammi region must have died out gradually as the area became 


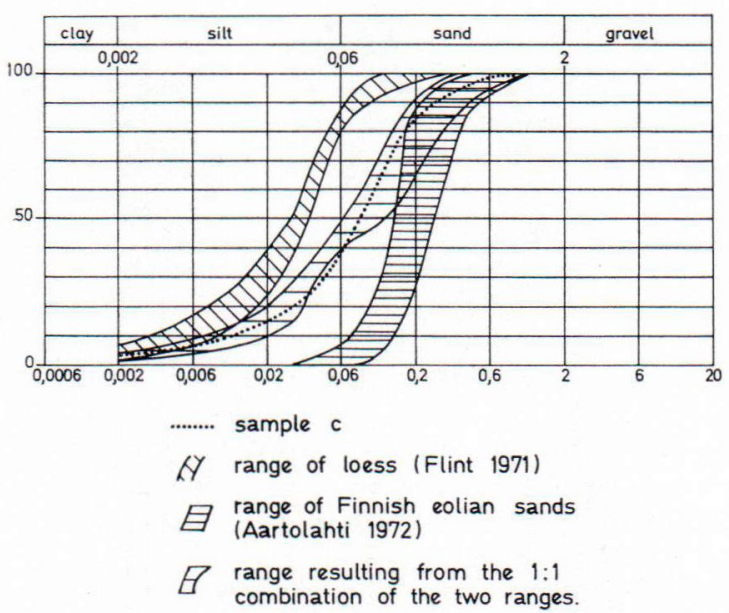

Fig. 13. An empirical approach illustrating the possible origin of the granulometric composition of sample c.

forested. The question now arises as to how long the period of eolization lasted. A preliminary morphoscopic examination of the silty base of a core from the nearby Lamminjärvi march seems to indicate that eolian deposition was still taking place towards the end of the Preboreal period. According to the pollen analysis made by Mrs. Irmeli Vuorela the NAP is still over $20 \%$ at this level, which suggests a fairly open landscape (see Alhonen and Vuorela 1974). Since the pollen zone boundary IV/V is dated to c. 8900 PB in Southern Finland (Donner 1971) the period of eolization can be estimated to have lasted between 500 and 1000 years.

\section{Concluding remarks}

Although no final conclusions can be drawn from the study of only three samples it is clear that the methods employed, especially SEM examination, may prove very useful in the reconstruction of the environmental history of the Lammi cover deposits. The study of the Onnenvuori samples gives good reasons to believe that the cover deposits, at least at Onnenvuori, can be related to the eolian processes which seem to have taken place after the drainage of the Baltic Ice Lake. On the basis of the results obtained the history of the Onnenvuori hill can be summarized as follows:

1) The Onnenvuori is formed as an extramarginal delta reaching up to the B III water level (c. $160 \mathrm{~m}$ a.s.1.). The ice margin continues its retreat and the delta is left submerged, its higher portion under the influence of wave action.

2) The drainage of the Baltic Ice Lake takes place and the Onnenvuori emerges as an island. Since the newly exposed landforms are unstable and devoid of vegetation cover, a period of intense erosional processes follows.

3) Solifluction and slope-washing processes work transporting their products downwards while eolian processes are not so dependent on gravity. Eolian action attacks the less protected slopes and accumulates the wind-blown drift on the more sheltered places. Part of the drift is deposited on dry land and part on water.

4) The eolian activity is gradually checked by the spread of forest into the region.

Aknowledgements - Mr. M. Koponen made available the facilities of the SEM Laboratory. Professor J. J. Donner made useful comments on the results obtained. Miss Maija-Leena Lukkariniemi assisted in polishing the English text. To all these we wish to express our most sincere thanks. 


\section{REFERENCES}

Aartolahti, T. (1972) On the beach ridges in the area of the Virttaankangas-Säkylänharju esker, SW-Finland. Fennia 117. 31 p.

Alhonen, P. and Vuorela, I. (1974) Lamminjärven kerrostumien siitepöly- ja piilevästratigrafia. Summary: On the pollen and diatom stratigraphy of the Flandrian sediments of Lamminjärvi, Southern Finland. Luonnon Tutkija 78: $40-47$.

Butzer, K. W. (1965) Environment and Archeology. Methuen, London. 524 p.

Cailleux, A. (1942) Les actions éoliennes périglaciaires quaternaires en Europe. Mém. de la Soc. Géol. de France, No. 46, 176 p.

- (1952) Morphoskopische Analyse der Geschiebe und Sandkörner und ihre Bedeutung für die Paläoklimatologie. Geol. Rundsch. 40; 11-19.

- (1959) Initiation a l'étude des sables et galets. Sorbonne, Paris, 3 volumes, 450 p.

- and Schneider, H. (1968) L'usure des sables vue a microscope électronique à balayage. 5 p.

Donner, J. J. (1969) Land/sea level changes in Southern Finland during the formation of the Salpausselkä endmoraines. Bull. Geol. Soc. Finland 41; 135-150.

- (1971) Towards a stratigraphical division of the Finnish Quaternary. Soc. Scient. Fennica, Comm. Physico-math. 41: 281-305.

Flint, R. F. (1971) Glacial and Quaternary Geology. John Wiley and Sons, New York. 892 p.

Jauhiainen, E. (1972) Lammin lössistä ja sen maanoksesta. Summary: The Lammi loess and its soil. Terra 84 (3): $152-160$.

Köster, E. (1964) Granulometrische und morphometrische Messmethoden. Stuttgart, 336 p.

Krinsley, D. H. and Donahue, J. (1968) Environmental interpretation of sand grain surface textures by electron microscopy. Bull. Geol. Soc. Am. 79: 743-748.

— and Margolis S. (1969) A study of quartz sand grain surface textures with the scanning microscope. Trans. New York Acad. Sci., Ser. 2, Vol. 31: 457-477.
- and Cavallero, L. (1970) Scanning electron microscopic examination of periglacial eolian sands from Long Island, New York. J. Sediment. Petrol. 40 (4): $1345-1350$.

- and Margolis, S. (1971) Submicroscopic frosting on eolian and subaqueous quartz sand grains. Bull. Geol. Soc. Am. 82 (12): 3 395-3 406. and Doornkamp, J. C. (1973) Atlas of quartz sand surface textures. Cambridge Univ. Press, 91 p.

NúNEZ, M. (1972) A palaeoclimatic interpretation from the fine fractions of the sediments of the Abri Pataud, Les Eyzies (Dordogne) France. Unpublished laudatur work in the library of the Dept. Geol. Paleontol. of the Univ. of Helsinki, pro gradu No. 82, 49 p.

Oкко, M. (1962) On the development of the First Salpausselkä west of Lahti. Bull. Comm. Geol. Finlande 202. $162 \mathrm{p}$.

- (1972) Jäätikön häviämistapa Toisen Salpausselän vyöhykkeessä Lammilla. Summary: Deglaciation in the Second Salpausselkä ice-marginal belt at Lammi, Southern Finland. Terra 84 (3): 115-123.

Окко, V. (1957 a) The Second Salpausselkä at Jylisjärvi, east of Hämeenlinna. Fennia 81 (4): 46 p.

- $(1957 \mathrm{~b})$ On the thermal behavior of some Finnish eskers. Fennia 81 (5): 38 p.

SEPPÄLÄ, M. (1969) On the grain size and roudness of wind-blown sands in Finland as compared with some Central European samples. Bull. Geol. Soc. Finland 41: $165-182$.

- (1971) Evolution of eolian relief of the KaamasjokiKielajoki river basin in Finnish Lapland. Fennia 104. $88 \mathrm{p}$.

Smalley, I. J. and TAylor, R. L. S. (1970) Loess - the yellow earth. Sci. J. Feb. 1970: 28-33.

Texier, J.-P. and Paquereau, M. M. (1973) Études sédimentologique et palynologique du gisement du Malpas, Commune de Bourniquel (Dordogne). L'Anthropologie. $77(1-2)$ : 35-62.

WiśnIEWSKr, E. (1973) The genesis of the Lammi esker (Southern Finland). Fennia 122. 31 p.

Manuscript received, January 24, 1974. 